\title{
Inhibition of the Wall-attached Fuel Combustion and the Formation of Aerosol Particle
}

Aerosol and Air Quality Research

\section{OPEN ACCESS}

Received: June 12, 2021

Revised: July 13, 2021

Accepted: July 19, 2021

${ }^{*}$ Corresponding Author: cbmsgml@gmail.com; sllin@bit.edu.cn

\section{Publisher:}

Taiwan Association for Aerosol Research

ISSN: $1680-8584$ print

ISSN: 2071-1409 online

Copyright: The Author(s). This is an open access article distributed under the terms of the Creative Commons Attribution License (CC BY 4.0), which permits unrestricted use, distribution, and reproduction in any medium, provided the original author and source are cited.

\author{
Han $\mathrm{Wu}^{1}$, Cong Liu ${ }^{1}$, Longmin Tang ${ }^{1}$, Chunze Cen ${ }^{2}$, Sheng-Lun Lin ${ }^{1 *}$, \\ Chien-Er Huang ${ }^{3}$ \\ ${ }^{1}$ School of Mechanical Engineering, Beijing Institute of Technology, Beijing 100081, China \\ ${ }^{2}$ Department of Mechanical, Aerospace and Civil Engineering, University of Manchester, M13 \\ 9PL, UK \\ ${ }^{3}$ Center for Environmental Toxin and Emerging-contaminant Research, Cheng Shiu University, \\ Kaohsiung 83347, Taiwan
}

\section{ABSTRACT}

The wall-attached fuel layer of the combustor usually leads to an unstable combustion and produces an unexpected emission, such as aerosol particles and unburn hydrocarbons. In this study, the impaction of ethanol droplet on a heated liquid surface was examined for investigating the factors those could effectively control the fuel atomization and avoided the formation of wallattached fuel layer. We accelerated the volatilization of ethanol droplets after contacting the liquid surface and even achieved the flash evaporation condition to burst the oil layer, which was conducive to cleaning the inner wall of the combustors and reducing emissions. A 3.12-mm ethanol droplet was used to impact a glycerol pool. The Weber number (WE, 303-1343) and pool temperature $\left(T, 50-260^{\circ} \mathrm{C}\right)$ were two controlled parameters to explore the impaction characteristics. There were four typical phenomena observed, including surface dissolving, penetrating dissolution, vapor explosions, and nucleate boiling. Results showed that the maximum volume and surface area of the crater increased with the $W E$ and the liquid pool temperature during impaction. Meanwhile, the boundary temperatures between the penetrating dissolution and the vapor explosion decreased. Additionally, the vapor explosion time increased with the WE but negatively correlated to the liquid pool temperature. The entire vapor explosion process was very short, lasting about 200 milliseconds. Furthermore, the increasing WE had a negative effect on the nucleate boiling intensity when the liquid pool temperature significantly enhanced it. Consequently, the fuel droplet atomization and explosion could be sensitively controlled by varying the $W E$ and the temperature of impaction surface. This finding provides valuable information to the designer of combustor control unit to inhibit and destroy the wall-attached fuel layer during the spry combustion and further inhibit the formation of combustion aerosol particles.

Keywords: Droplet impaction, Weber number, Liquid surface temperature, Vapor explosion, Nucleate boiling

\section{INTRODUCTION}

Cleaner and more efficient combustion technique has always been a popular topic with the increasing environmental pollution issue and carbon neutrality consideration (Chen et al., 2020; Kuo et al., 2019; Tsai et al., 2015, 2020; Yao et al., 2009). Indirect injection engines, which have high efficiency, low emission, and structural miniaturization, the droplets in the spray can easily impact the piston and the cylinder wall to forming a wall-attached fuel layer with its high injection pressure. This is considered as a main cause of carbon emissions and knocking problem (Panão and Moreira, 2005; Shinjo and Xia, 2017; Wang et al., 2016; Zhi Wang et al., 2017a).

The fuel droplets may impact the surface of the liquid fuel when there is a fuel layer on the inner wall of the combustion chamber. Thus, it is important to investigate the impact behaviors, 
mechanisms, and control techniques to improve the combustion characteristics and emissions. The impaction of droplets on a liquid surface is a complicated process involving heat transfer, mass transfer, and phase transitions. Generally, droplets are easily affected by the properties of the liquid droplet (size, viscosity, surface tension, density, and impaction velocity), and pool conditions (temperature and depth), which have been widely studied (Fan et al., 2019; Lee et al., 2020; Rein, 1993).

Ethanol has been widely used as an additive in conventional fuels. The physical and chemical properties, combustion characteristics, and emission profiles of ethanol-fossil fuel blends had been explored (He et al., 2003; Mao et al., 2019; Masum et al., 2013). The addition of ethanol to diesel reduced the density, cetane value, kinematic viscosity, high calorific value and aromatic fraction of the fuel, while they increase the octane value and fuel oxygen content of gasoline blends to shorten the ignition delay time, and effectively reduce the emissions of soot, $\mathrm{NO}_{\mathrm{x}}$, and $\mathrm{CO}_{2}$. Additionally, the ethanol could represent certain parts of the oxygenated short-chain fuel additives while it had oxygen content, low density and viscosity, lower vapor pressure (relative to diesel and gasoline). Therefore, the ethanol droplets were used to observe the fuel-liquid layer impaction in this study.

Leng (2001) established the distribution map of the droplet impaction phenomenon jointly determined by the Weber number $(W E)$ and the Froude number by varying the released heights and diameters of the water droplet. As the $W E$ and Froude number increased, the dominant phenomena were shifted from bouncing, floating, and coalescing to vortex rings, jets, splashes, and bubbles.

$\mathrm{Xu}$ et al. (2016) carried out experiments of water droplets impacting a burning fuel liquid surface with the background of fire extinguishing. They show that the maximum crater depth, width, and jet height increased slightly when the impaction velocity increased from $2.351 \mathrm{~m} \mathrm{~s}^{-1}$ to $3.357 \mathrm{~m} \mathrm{~s}^{-1}$ and further significantly enhanced by more rapid impaction $\left(3.513 \mathrm{~m} \mathrm{~s}^{-1}\right)$. Under different WEs and liquid depths, three typical impact regimes were observed when a single droplet hit the heptane pool, including penetration-secondary penetration/floating, crater-jet/crater-jetsecondary jet and bubble. Penetration only occurred at low WEs. As the WE increased from 175 to 440, a crater-jet appeared in the shallow pool, and a crater-jet-secondary jet appeared in the deep pool. When the WE exceeded 564, bubbles began to form (Fan et al., 2018). In addition, Lan and Wang (2014) used experimental and numerical simulation methods to study the impaction of a single water droplet on the heated wood surface. The maximum rebound height increased with the $W E$, which should higher than a certain level.

The temperature of the liquid pool may also affect these phenomena. An experimental study was presented for water and methoxy-nonafluorobutane C4F9OCH3 (HFE-7100) droplets impacting on a heated pool of cooking oil. It was observed that water droplet produced a vapor explosion at $220^{\circ} \mathrm{C}$, but the HFE-7100 droplet did not explode when oil was above $180^{\circ} \mathrm{C}$ (Manzello et al., 2003). Xu et al. (2018a) conducted a series of experiments on single water droplet impaction on a hot ethanol surface. Three impact regimes including crater-jet, penetration and surface bubble were observed. The crater-jet appeared under low-speed impact. When the liquid pool temperature exceeded $50^{\circ} \mathrm{C}$ under a low $W E$, penetration phenomenon occurred. And for surface bubble regime, it occurred when the water droplet at lager velocity impacted on the hot ethanol surface. The effects of temperature and WE on the crown height and the energy conversion rate during the crater evolution and the jet evolution were also studied. Xu et al. (2019) conducted studies on the collision dynamics of the single droplet with or without additives impinging on unburned or burning oil pool. Vapor explosion occurred when the oil temperature exceeded $210^{\circ} \mathrm{C}$ which resulted in flame expansion for droplet impacting on burning oil pool. The flame expansion intensity ranked as pure water droplet $>$ water droplet with $5 \%$ sodium chloride $(\mathrm{NaCl})>$ water droplet with $3 \%$ aqueous film forming foam. However, there have been limited studies focusing on the low-density droplet impacting on high-density liquid, which is more representative to the fuel spray atomization and the wall-attached fuel layer issue.

The evaporation of the wall-attached oil film will affect the heat flux of the engine wall. At the same time, the oil film vapor participates in the combustion, which can significantly change the fuel-gas equivalent ratio near the wall, leading to incomplete combustion, and then affecting the aerosol particle emissions. Stevens and Steeper (2001) used laser-induced fluorescence technology to study the piston wet wall effect on DISI engines and found that local fire caused by oil film evaporation is an important source of particulate matter emissions. Chin and Lee (2002) pointed 
out that the wall oil film on the cylinder liner under the exhaust valve and the top of the piston was the main source of unburned hydrocarbons.

Martin et al. (2008) studied the low-temperature combustion emission characteristics of diesel engines. The results showed that at low cylinder temperature, the liquid fuel impacted the surface of the piston to form a wall-attached oil film. After the release of a large amount of heat was over, the previous combustion stage caused the oil film attached to the combustion chamber to form a pool fire. Analyzing the emission results showed that there was a strong correlation between the emission and the intensity of the pool fire. As the intensity of the pool fire increased, soot and NOx emissions gradually increased.

An ethanol droplet and a glycerol pool were employed in the current study to investigate the impaction behavior between the low-density alcohol and the high-density heated liquid. Since both ethanol and glycerol are transparent and colorless, the phenomena could be easily observed at the compaction interface. The boiling point and density of ethanol are significantly lower than those of glycerol, leading to a wide range of testing temperatures. The experiment was carried out under different $W E$ and liquid pool temperature conditions. Process images of each impact behavior were collected. The critical conditions for the transitions between different behaviors are stated. Furthermore, the effects of WE and temperature on the crater volume, surface area, the vapor explosion time, and nucleate boiling intensity are comprehensively discussed.

\section{MATERIALS AND METHODS}

The experimental system was composed of a high-speed camera, a heater device, a container, a lighting system, a droplet generator, and a computer. A schematic diagram is shown in Fig. 1. Pure ethanol (purity $\geq 99.7 \%$, Macklin Inc.) was drawn at $0.15 \mathrm{~mm} \mathrm{~s}^{-1}$ with a syringe driven by a pump to produce droplets. The droplet diameters were fixed at $3.12 \pm 0.0078 \mathrm{~mm}$ with a $1.96 \mathrm{~mm}$ needle. The relevant properties of ethanol are shown in Table 1. To obtain different impact velocities in the ethanol droplets, the distance between the needle and the liquid pool surface was set to $15,25,35,45,55,65$, and $75 \mathrm{~cm}$. The entire experiment was conducted at room temperature and at atmospheric pressure.

Pure glycerol (purity 99.7\%, Tianjin Zhiyuan Chemical Reagent Co., Ltd.) was put in a transparent quartz glass tank $(50 \times 50 \times 60 \mathrm{~mm})$ at a $30-\mathrm{mm}$ depth to form an impacted liquid pool. The boiling point of glycerol is $290^{\circ} \mathrm{C}$, and its other properties are also displayed in Table 1 . A thermostat heater device was used to heat the glycerol pool to $50-260^{\circ} \mathrm{C}$. Three $0.5-\mathrm{mm}$-diameter, K-type thermocouples (accuracy $=0.5^{\circ} \mathrm{C}$ ) were placed $7 \mathrm{~mm}, 15 \mathrm{~mm}$, and $23 \mathrm{~mm}$ under the surface of

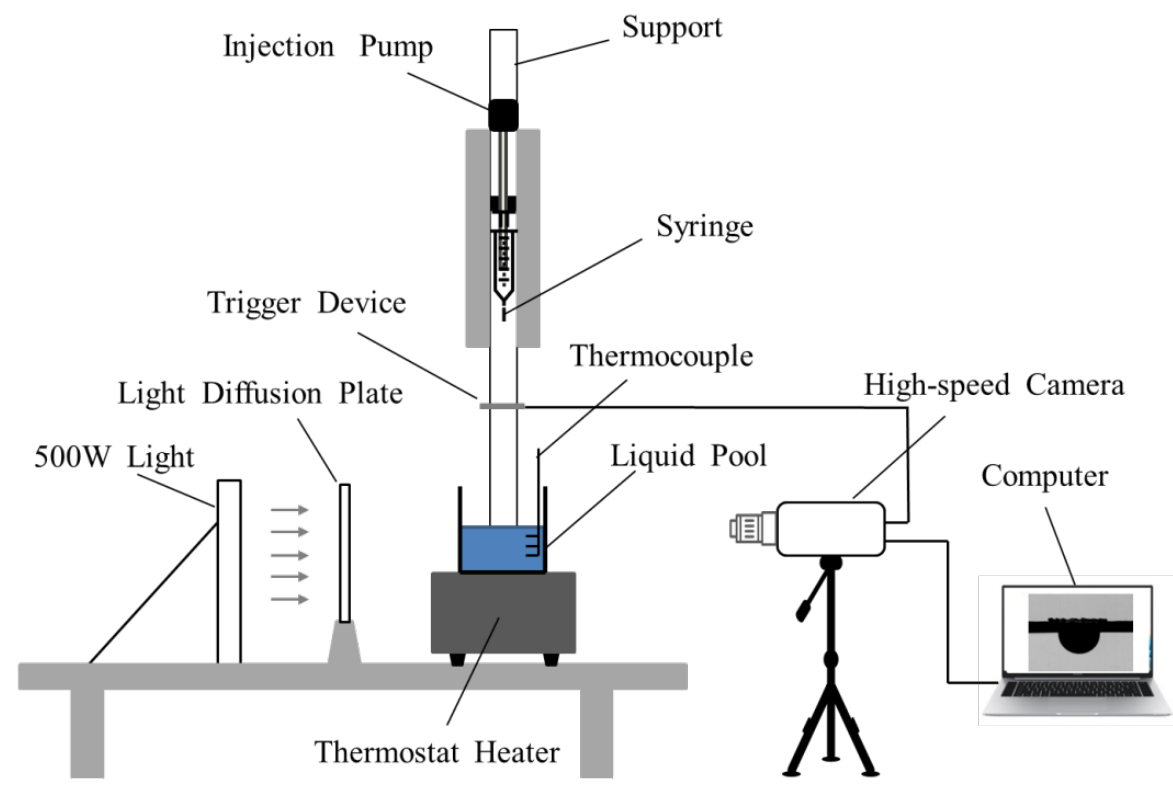

Fig. 1. Schematic diagram of the experimental setup. 
Table 1. Physical properties of ethanol and glycerol.

\begin{tabular}{lcc}
\hline Droplet & Ethanol & Glycerol \\
\hline Density $\left(25^{\circ} \mathrm{C}\right)\left(\mathrm{g} \mathrm{mL}^{-1}\right)$ & 0.785 & 1.26 \\
Viscosity $(\mathrm{mPa} \cdot \mathrm{s})$ & & \\
$25^{\circ} \mathrm{C}$ & 1.048 & 954 \\
$50^{\circ} \mathrm{C}$ & & 142 \\
$60^{\circ} \mathrm{C}$ & & 81.3 \\
$70^{\circ} \mathrm{C}$ & & 50.6 \\
$80^{\circ} \mathrm{C}$ & & 31.9 \\
$90^{\circ} \mathrm{C}$ & & 21.3 \\
$100^{\circ} \mathrm{C}$ & & 14.8 \\
Surface tension $\left(\mathrm{mN} \mathrm{m}^{-1}\right)$ & & \\
$25^{\circ} \mathrm{C}$ & 22.4 & 62.2 \\
$50^{\circ} \mathrm{C}$ & & 61.1 \\
$60^{\circ} \mathrm{C}$ & & 60.3 \\
$70^{\circ} \mathrm{C}$ & & 59.4 \\
$80^{\circ} \mathrm{C}$ & & 58.7 \\
$90^{\circ} \mathrm{C}$ & & 57.9 \\
$100^{\circ} \mathrm{C}$ & & 57.1 \\
Boiling point $\left({ }^{\circ} \mathrm{C}\right)$ & 290 \\
\hline
\end{tabular}

the liquid in the heated liquid pool to monitor the real-time vertical temperature distribution. The temperature difference between $23 \mathrm{~mm}$ and $7 \mathrm{~mm}$ was at most $3 \pm 0.5^{\circ} \mathrm{C}$, and recorded the temperature at $15 \mathrm{~mm}$ as the liquid pool temperature. Each condition was repeated three times to ensure its reliability.

A high-speed digital camera (MacroVis EoSens) with a Tamron $180 \mathrm{~mm}$ microlens was employed to record the dynamic process of an individual droplet impacting the liquid surface, and a $496 \times$ 500-pixel resolution, $5134 \mathrm{fps}$, and $192 \mu \mathrm{s}$ exposure time were set as the working conditions. A 500-W LED light was placed on the opposite side of the high-speed video camera to illuminate the droplet impaction. A polycarbonate light diffusion plate was placed between the experimental object and the light source to obtain uniformly distributed light. The signal control system consisted of a trigger device and a computer, which controlled the trigger time of the camera to ensure that the impact process was completely recorded.

The velocity of the droplet contacting the liquid surface was calculated with a MATLAB code based on the recorded images. 20 consecutive frames of images before the droplet touches the wall were selected. The ordinate of the center of the droplet in each frame of image was obtained through Hough transform, and subtracted the ordinate of the surface of the liquid pool to obtain the distance between the center of the droplet and the surface of the liquid pool. The interval time between each frame can be known by the camera shooting speed, so the droplet velocitytime diagram can be obtained by the stepwise difference method, and the final velocity of the droplet impacting the liquid surface was obtained by fitting. More setting details can be referred to in a previous study (Cen et al., 2019). The droplet velocities at impaction on the surface for the various droplet release heights were 1.66, 2.07, 2.40, 2.79, 3.01, 3.31, and $3.50 \mathrm{~m} \mathrm{~s}^{-1}$. Thus, the WEs were calculated to be $303,466,628,849,991,1195$, and 1343 , respectively.

\section{RESULTS AND DISCUSSION}

\subsection{Typical Phenomena at the Impaction Surface}

Phenomena below the liquid level were mainly the concern in this experiment. Four typical impact behaviors were recorded in sequence as the temperature of the liquid pool was increased, including surface dissolving, penetrating dissolution, vapor explosions, and nucleate boiling.

\subsubsection{Surface dissolving}

When the liquid pool temperature was low, only surface dissolving occurred. Fig. 2 provides a 


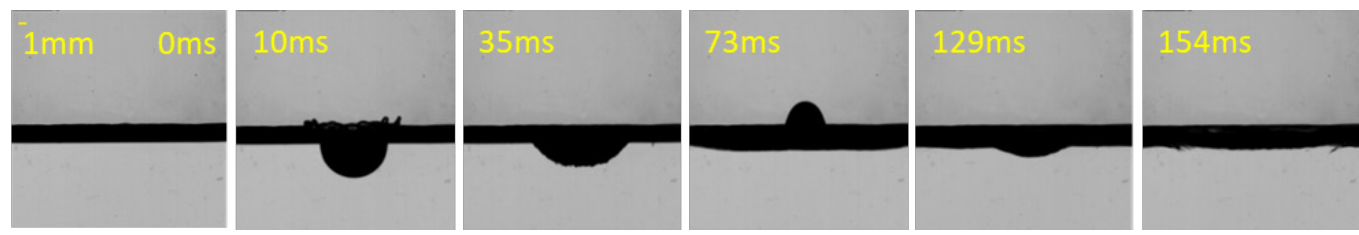

Fig. 2. Surface dissolving during ethanol droplet interaction with glycerol ( $\left.W E=849, T=80^{\circ} \mathrm{C}\right)$.

case with $W E=849$ and $T=80^{\circ} \mathrm{C}$. The time when the droplet contacts the liquid surface is defined as $0 \mathrm{~ms}$ (millisecond). The glycerol liquid around the impact point was squeezed to form a crater structure beneath the surface at $10 \mathrm{~ms}$, and when the crater reached its maximum size, the liquids near the crater began to fill the crater at $35 \mathrm{~ms}$, after which a jet rose from the free surface until it reached a maximum height of $73 \mathrm{~ms}$. After the jet descended, it diffused and dissolved on the surface of the liquid pool at $154 \mathrm{~ms}$. This entire process is called surface dissolving. During this process, the droplet cannot penetrate the liquid surface, so it can only dissolve on the surface. The main reason for this is that the density of the ethanol droplet is less than the density of the glycerol liquid. In addition, the low temperature leads to high viscosity and surface tension in the liquid pool, which are resistant to droplet collision. The greater viscosity and surface tension lead to less surface deformation at the point of impaction. Therefore, it can be seen that when the surface temperature is low, surface dissolving will occur, forming a wall-attached fuel film layer. In addition, a low WE will also enhance the wall-attached fuel layer formation. The smaller droplet diameter and lower impact velocity will result in a lower WE.

\subsubsection{Penetrating dissolution}

As the pool temperature increased, a penetrating dissolution phenomenon was observed. Fig. 3 displays an ethanol droplet impacting a glycerol surface with $W E=849$ and $T=160^{\circ} \mathrm{C}$. Compared with the case of low pool temperature in Fig. 2, this case also includes the formation and contraction of the crater and the rise and fall of the jet, but there is an obvious difference in that the jet liquid penetrates the target surface at $136 \mathrm{~ms}$, and then dissolves inside the liquid pool at $174 \mathrm{~ms}$. This evolutionary process is called penetrating dissolution. Another obvious difference is that during the shrinking process at $t=35 \mathrm{~ms}$, the surface of the crater in Fig. 3 was rougher than that in Fig. 2 . This was because the increase in temperature accelerated the diffusion and dissolution of droplets.

In terms of the surface dissolving and the penetrating dissolution, the main reason for the difference between the two was the change in the liquid pool temperature. The surface tension and viscosity of the liquid in the pool decreased with increases in temperature (as shown in Table 1). The smaller surface tension and viscous force reduced the hindrance of the droplet impaction process. The initial kinetic energy dissipation of the droplet was reduced, resulting in more energy for the subsequent jet generation. Thus, the maximum jet height in Fig. 3 was significantly higher than that in Fig. 2, which caused Fig. 3 easier to penetrate the liquid surface when the jet descended. Thus, the droplet could penetrate the surface and dissolve in cases of low surface tension and viscosity.

\subsubsection{Vapor explosion}

As the pool temperature was increased to $180^{\circ} \mathrm{C}$, a significantly different vapor explosion phenomenon was observed. Fig. 4(a) presents the entire vapor explosion process as the ethanol droplet impacted the hot glycerol liquid pool $\left(W E=849, T=185^{\circ} \mathrm{C}\right)$. A vapor explosion occurred at $130 \mathrm{~ms}$, and then a cavity formed and expanded rapidly at $133 \mathrm{~ms}$ and $135 \mathrm{~ms}$. Numbers of
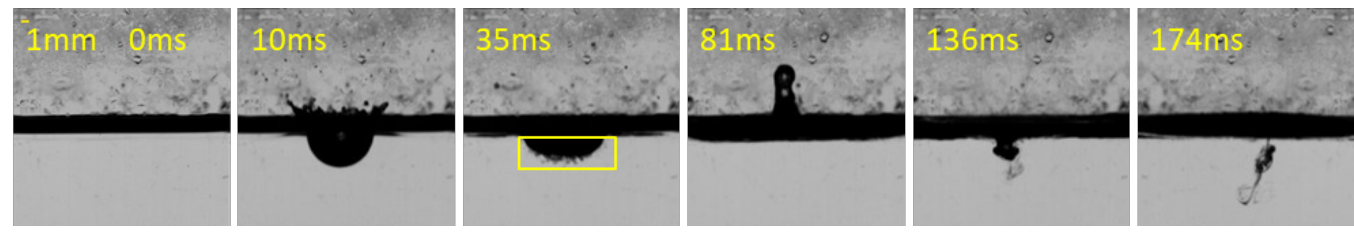

Fig. 3. Penetrating dissolution during ethanol droplet interaction with glycerol. ( $\left.W E=849, T=160^{\circ} \mathrm{C}\right)$. 

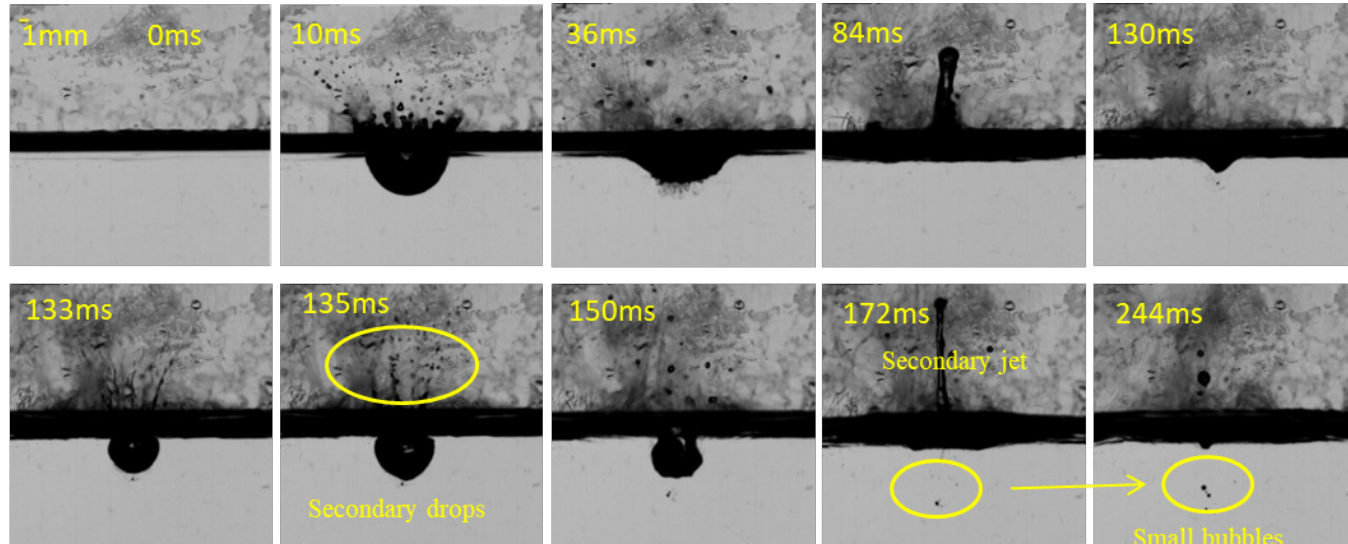

(a) Vapor explosion during ethanol droplet interaction wit
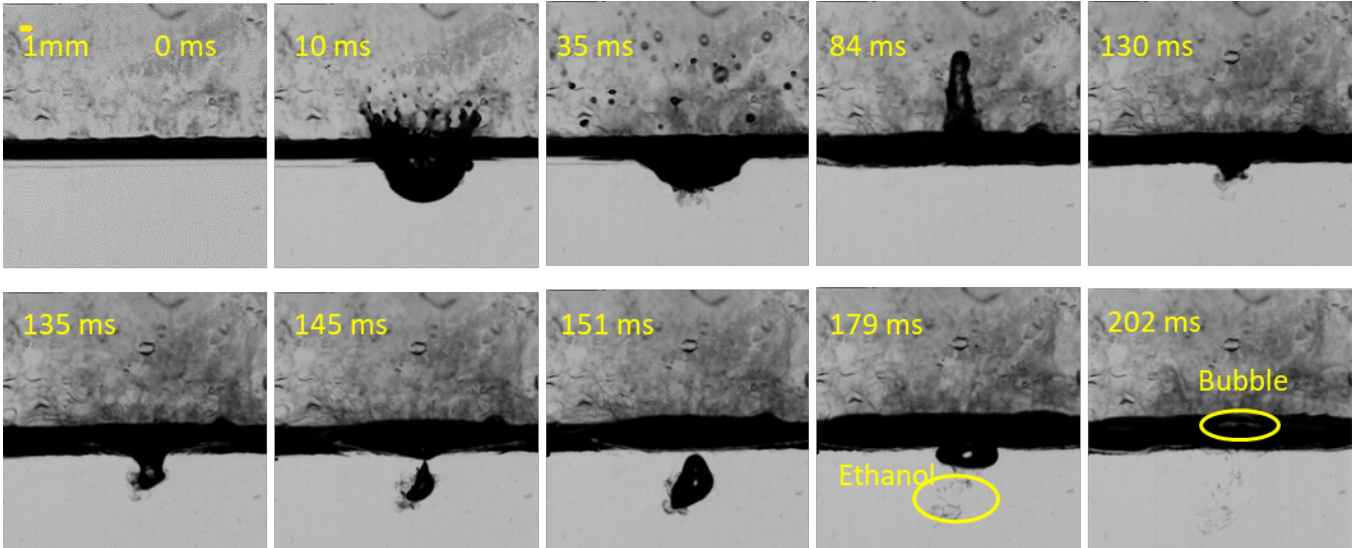

(b) Vapor explosion during ethanol droplet interaction with glycerol. (WE $\left.=991, T=183^{\circ} \mathrm{C}\right)$

Fig. 4. Vapor explosion ethanol droplet interaction with glycerol.

secondary droplets were generated during the process. When the crater size reached its maximum, it began to shrink, and then a secondary jet formed, as shown in the picture at $172 \mathrm{~ms}$. At $244 \mathrm{~ms}$ the broken ethanol droplets produced by the vapor explosion evaporated into small bubbles, which eventually rose to the liquid surface and broke. Due to the vapor explosion, the free liquid surface fluctuated significantly. It took a few hundred milliseconds for the surface of the liquid pool to calm down, which was obviously shorter than the thousands of milliseconds discussed in previous studies (Fan et al., 2021; Manzello et al., 2003; Wang et al., 2017b; Xu et al., 2019, 2018b). Fig. 4(b) presents another series of images at $W E=991$ and $T=183^{\circ} \mathrm{C}$. In contrast to the former case, a bubble was generated at $135 \mathrm{~ms}$, which broke away from the target liquid at $145 \mathrm{~ms}$ The bubble expanded in the liquid pool and rose continuously until it finally floated on the liquid surface at $199 \mathrm{~ms}$. After remaining there for a while, it collapsed. Interestingly, no secondary droplets or secondary jets were generated during the entire process.

The vapor explosion was caused by the evaporation of the cold ethanol droplet within the hot liquid pool (Wang et al., 2017b). After the crater shrank, part of the initial ethanol droplet gathered on the top of the jet (Fang and Chen, 2019). Furthermore, the ethanol rapidly evaporated into its gaseous phase and created cavities on the glycerol surface when the top of the jet dropped back to the surface level. A large number of high-temperature glycerol droplets then splashed due to the vapor explosion when the WE was 849. Practically, the ethanol droplet had enough energy to penetrate the liquid surface and approach the above reaction when the $W E$ increased to 99; thus, there were no splashing glycerol droplets.

\subsubsection{Nucleate boiling}

Nucleate boiling of the ethanol droplet was found in the high temperature case, which had been found in Alchalabi's research. Fig. 5 presents a set of images under $W E=849, T=220^{\circ} \mathrm{C}$. An 


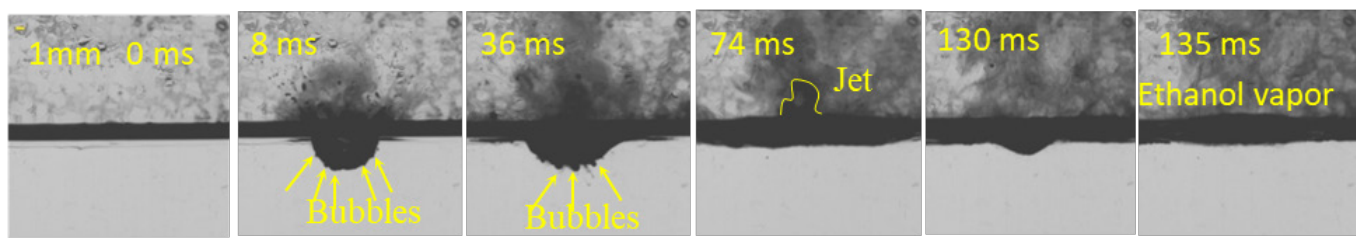

Fig. 5. Nucleate boiling during ethanol droplet interaction with glycerol. ( $W E=849, T=220^{\circ} \mathrm{C}$ ).

obvious feature is that a large number of vapor bubbles were continuously produced and collapsed during the formation $(8 \mathrm{~ms})$ and contraction $(36 \mathrm{~ms})$ of the crater after the droplet touched the liquid surface. The jet was still generated, but only a small crater formed after the jet descended at $130 \mathrm{~ms}$ and the vapor explosion no longer occurred. Also, the vapor produced by the evaporation of ethanol could be clearly seen throughout the process occurring above the liquid surface.

Obvious temperature differences between the droplet and the liquid pool greatly increased the heat flux and accelerated the droplet heat absorption from the liquid pool. Thus, the droplet immediately evaporated when it entered the liquid pool, in turn displaying nucleate boiling. The ethanol was almost completely consumed by evaporation during the crater period, and almost no vapor explosion could be observed after the jet flowed down. During the nucleate boiling process, the droplet evaporated quickly, which would make the combustion more complete and reduce the formation of aerosol particles.

\subsection{Crater Characteristics for Surface Dissolving}

Although many studies have focused on the maximum crater depth and width when a single droplet impacts a liquid pool (Fan et al., 2019; Xu et al., 2016, 2017), the maximum crater volume and surface area, which integrate the depth and width of the crater, are typically not taken into consideration. Fig. 6 presents the maximum crater volume and surface area as a function of pool temperature under various Wes. A MATLAB program was used to count the number of pixels in the crater plane area captured by the camera, where the crater was regarded as a space formed by the rotation of the two-dimensional plane. The actual volume $(\mathrm{V})$ and surface area $(\mathrm{S})$ of the crater were calculated using Eqs. (1) and (2):

$$
\begin{aligned}
& V=\frac{\pi}{4} l^{2} \cdot \sum_{i=1}^{n} m_{i}^{2} \\
& S=\pi l^{2} \cdot \sum_{i=1}^{n} m_{i}
\end{aligned}
$$

where $I, n$, and $m_{i}$ represent the actual length of each pixel, the total number of rows, and the number of pixels in the $\mathrm{i}^{\text {th }}$ row of the crater, respectively.

As shown in panels (a) and (b), when the temperature is constant, increasing the WE can increase the maximum crater volume and surface area, which is consistent with Hasegawa and Nara 's (2019) conclusion. During the droplet collision with the liquid surface, the kinetic energy of the droplet is partially converted to the energy necessary to support the formation of the crater, as well as to other wasteful forms of energy, such as surface energy, dissipated viscous energy, and wave-swell energy (Hasegawa and Nara, 2019). Approximately $28 \%$ of the impact kinetic energy is converted to crater potential energy (Leng, 2001), which means that the WE increases; that is, the greater the initial kinetic energy of the droplet, the more energy is used to form the crater, so the maximum crater volume and surface area increase accordingly.

The effect of temperature on the maximum volume and surface area of the crater was of interest in this work. The results show that as the temperature increased, the maximum volume and surface area also increased. Since the physical properties of the target liquid depend on its temperature, an increase in the temperature will reduce the surface tension and viscous force, which results in a decrease in the resistance to droplet collision. 

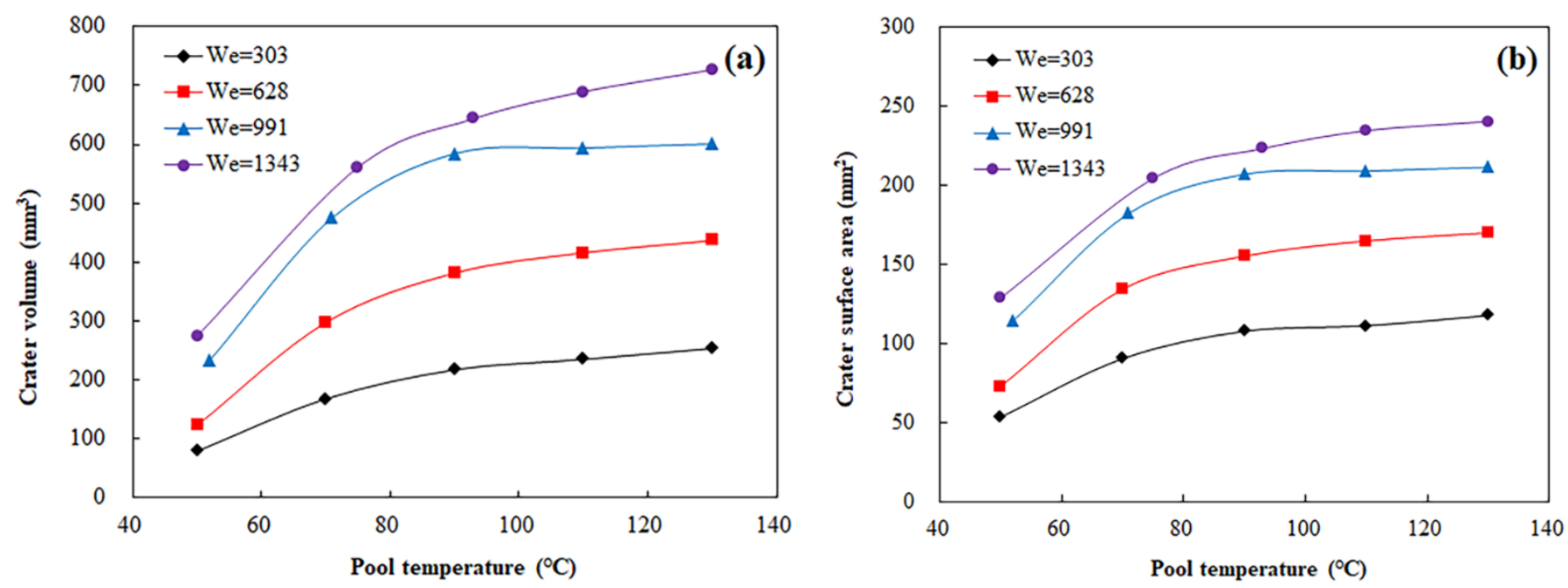

Fig. 6. (a) Maximum crater volume and (b) surface area at various pool temperatures.

These results confirm that the maximum volume and surface area are affected by the $W E$ and liquid pool temperature. What cannot be ignored is that the growth rate of the maximum volume and surface area decrease as the WE or temperature increase. The growth rates of the maximum volume with the $W E$ were $76.9 \%, 42.8 \%$, and $16.1 \%$, respectively, when the liquid temperature was $130^{\circ} \mathrm{C}$, and the growth rates of the maximum volume with the liquid temperature were $103.2 \%, 22.9 \%, 1.6 \%, 1.2 \%$, respectively, when the $W E$ was 628 . This indicates that the $W E$ and temperature have a limited effect on the maximum volume and surface area of the crater.

\subsection{Critical Temperatures for Two Regions}

The four typical impact phenomena discussed above are shown in Fig. 7 based on the WE and the temperature of the liquid pool. The WE-to-T map is subdivided into five regions: surface dissolving, penetrating dissolution, penetrating dissolution and vapor explosion, vapor explosion, and nucleate boiling. What needs to be pointed out is that penetrating dissolution and vapor explosion occur in a transition region for the two impact behaviors. In this region, the two phenomena occur alternately.

It can be seen from Fig. 7 that the pool temperature for penetrating dissolution decreased with increased in the $W E$. The main reason for this may be that as the $W E$ increased, the initial impact energy of the droplet was greater, so it was easier for the droplet to overcome the viscosity and surface tension of glycerol and penetrate the liquid surface of the pool. Therefore, as the WE increased, the critical pool temperature for penetrating dissolution decreased.

The effect of the WE on the critical temperature for vapor explosion is analyzed. Table 2 shows the experiments from other studies, where the results show that the critical temperature was a fixed value. In experiments of Manzello et al. (2003) and Wang et al. (2017b), the WEs were fixed. In Xu's experiment, the falling height and WE varied, but when the WE was increased, an experiment where the liquid pool temperature was lower than the critical temperature was not done, so the relationship between the WE and the critical temperature cannot be determined (Xu et al., 2018b). As shown in Fig. 7, the critical temperature decreased as the WE increased. With a small $W E$, the contact time and area of the droplet and the liquid pool were small, so a large temperature difference was required for the droplet to absorb enough heat to cause a vapor explosion, that is, the critical temperature was high. With the increase of the $W E$, the contact time and area increased, and the heat absorption increased (Fang and Chen, 2019), vapor explosion could occur at lower liquid pool temperature. Therefore, the critical temperature for vapor explosion decreases with the increase of WE.

\subsection{Vapor Explosion Time}

The vapor explosion time is defined as the period from the droplet contacts the liquid surface to the point at which gas bubbles develop from the liquid droplet and begin swelling (the 


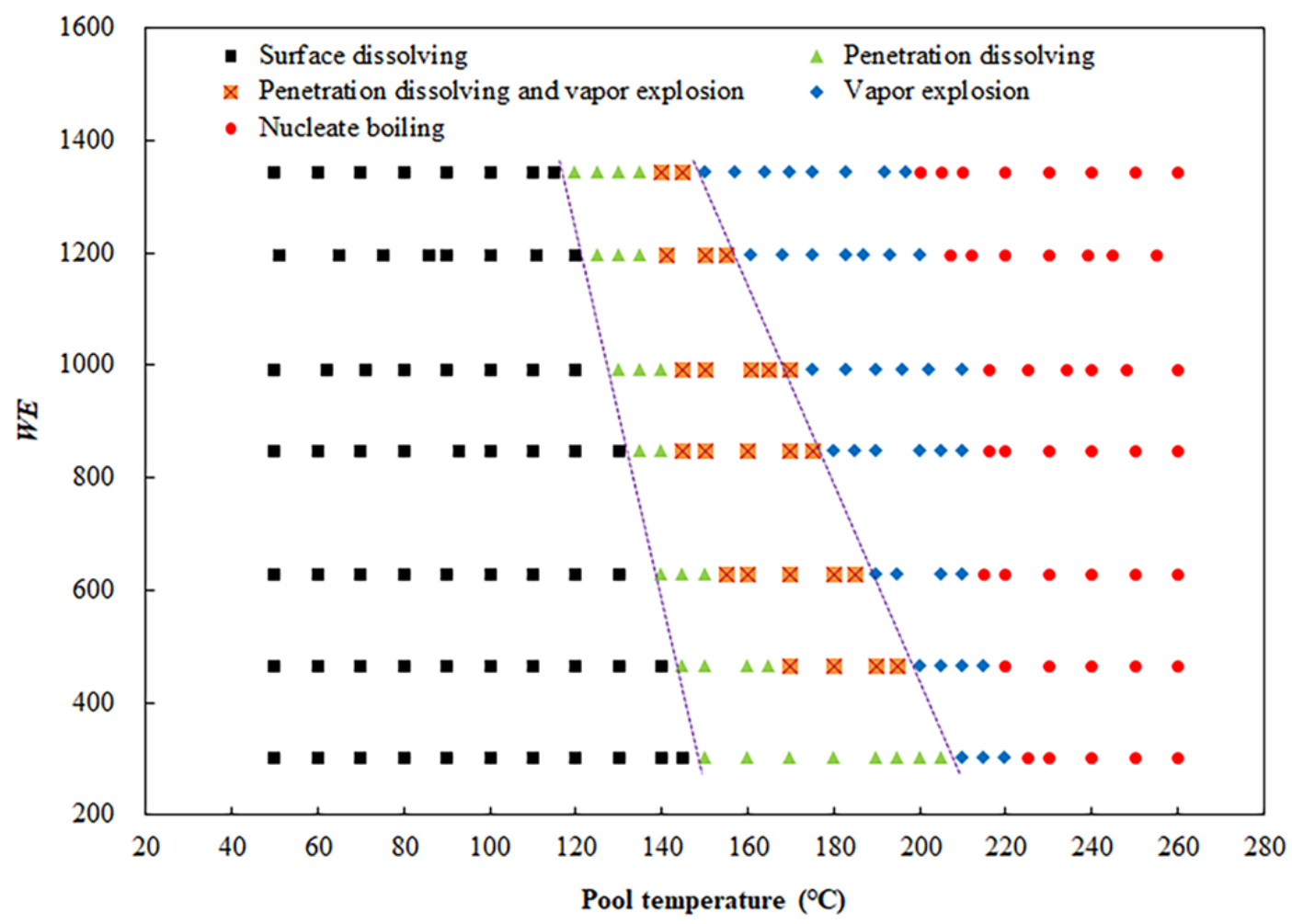

Fig. 7. Five regions under different conditions.

Table 2. Critical temperature for a vapor explosion.

\begin{tabular}{llllll}
\hline Experiments & Droplet & Impact $W E$ & Pool liquid & Pool temperature & Critical temperature \\
\hline Present & Ethanol & $W E=303-1343$ & Glycerol & $50-260^{\circ} \mathrm{C}$ & Varies with $W E$ \\
Xu et al. (2018b) & Water & $W E=213-571$ & Rapeseed oil & $205-260^{\circ} \mathrm{C}$ & About $210^{\circ} \mathrm{C}$ \\
Wang et al. (2017b) & Water & $W E=258$ & Molten ghee & 120,160 , and $220^{\circ} \mathrm{C}$ & About $220^{\circ} \mathrm{C}$ \\
& $5 \% ~ N a C l$ & $W E=299$ & & 120,160 , and $220^{\circ} \mathrm{C}$ & About $220^{\circ} \mathrm{C}$ \\
Manzello et al. (2003) & Water & $W E=200$ & Peanut oil & $220^{\circ} \mathrm{C}$ & About $220^{\circ} \mathrm{C}$ \\
& HFE-7100 & $W E=188$ & & $140-220^{\circ} \mathrm{C}$ & About $140^{\circ} \mathrm{C}$ \\
\hline
\end{tabular}

beginning of the vapor explosion). The results for the vapor explosion time at various WEs and pool temperatures are shown in Fig. 8, including the cases with a vapor explosion in the transition region.

It can be seen from Fig. 8 that the time required for a vapor explosion was less than $200 \mathrm{~ms}$. In previous studies (Fan et al., 2021; Manzello et al., 2003; Wang et al., 2017b; Xu et al., 2018b, 2019), the vapor explosion time was much higher than that found in this experiment. In addition, the vapor explosion time increased with increases in the droplet $W E$ at a fixed temperature in the current experiment. However, Xu et al. (2018b) indicated that the explosion time decreased as the $W E$ increased, conflicting with our findings. This could be due to the differences in the density of the droplet and the pool liquid. In Xu's experiment, the density of the droplet was greater than the density of the target liquid. After a droplet falls, it penetrates the crater bottom, where the crater develops to its maximum depth and continues to fall until it reaches the pool bottom. As the falling height increases, the falling speed of the droplet also increases, which in turn shortens the time required for the droplet to reach the bottom of the oil pool, where the droplet not only can absorb heat from the oil but can also absorb heat from the bottom wall sooner (Xu et al., 2018b). In the current experiment, the density of the ethanol droplets was less than the density of the glycerol liquid pool. As shown in Fig. 4, the droplet fluid had gone through crater formation, crater retraction, jet ascending, and jet descent process before it began to penetrate the target liquid surface. When the WE is larger, a larger crater is generated (refer to Fig. 6) as well as a 


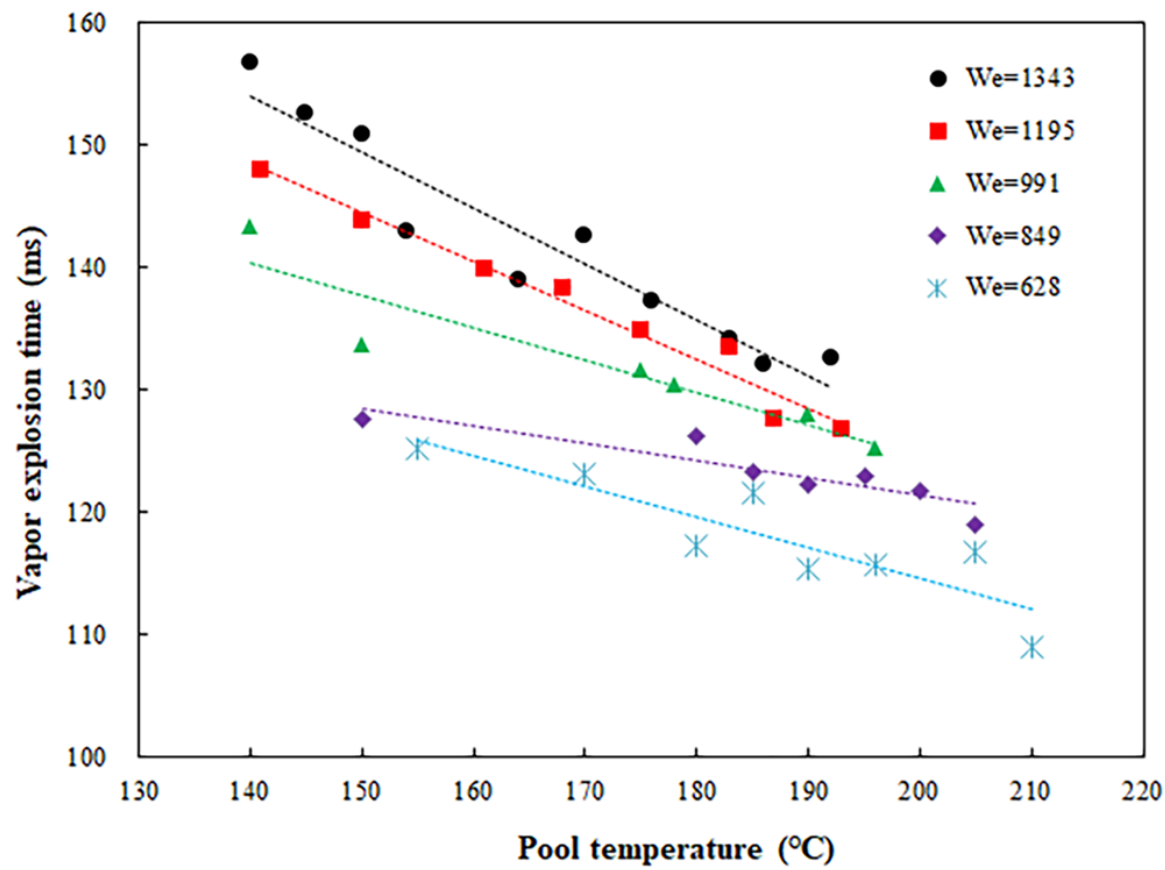

Fig. 8. Vapor explosion time as a function of pool temperature.

higher the jet (Fan et al., 2018; Manzello and Yang, 2002), so the formation and retraction of the crater and the rise and fall of the jet will take more time. The time for the jet to completely fall to the liquid surface was obtained from the test video $\left(T=150^{\circ} \mathrm{C}\right.$. $W E=849$, Time $=119 \mathrm{~ms} ; W E=$ 991, Time $=125 \mathrm{~ms} ; W E=1195$, Time $=131 \mathrm{~ms} ; W E=1343$, Time $=135 \mathrm{~ms})$. Therefore, the explosion time increased as the $W E$ increased.

Additionally, Fig. 8 suggests that the explosion time decreased with increases in the pool temperature at a fixed $W E$, which is consistent with the conclusions drawn in other papers (Wang et al., 2017b; Xu et al., 2018b). A higher pool temperature creates a larger temperature difference, which speeds up the temperature rise in the ethanol droplet. Therefore, the droplet can undergo a phase change earlier at higher pool temperatures.

\subsection{Intensity of Nucleate Boiling}

The interactions between the surface and droplets (with various WEs) were observed at $17 \mathrm{~ms}$ after impaction (as shown in Fig. 9). The results show that the crater deformed seriously at low WEs, while there was less vapor above the liquid surface. The effect of thermodynamics could have been greater than that of dynamics since the initial kinetic energy was small. In terms of appearance, the droplets boiled immediately after they touched the pool surface and then rapidly evaporated. The bubbles were continuously generated and collapsed, resulting in serious crater deformation. However, the nucleate boiling calmed down quickly as the crater shrank and pulled the ethanol back to the liquid phase. This could have resulted from the lower density and smaller momentum of ethanol droplet and the eventual release of a small amount of vapor. At high WEs, the dynamics could potentially be more effective in terms of the surface interaction than thermodynamics. It was observed that at different WEs for the same liquid temperature, fewer nucleation sites were activated for the higher WE case. Because of the high impact velocity, the crater deformation was minor under a stable impact force, and the ethanol boiled vigorously for a long time in the liquid pool, causing a large amount of vapor to be produced.

Fig. 10 displays the nucleate boiling phenomenon at different temperatures. It can be seen that as the temperature was increased, there were more ethanol bubbles around the crater, resulting in severe deformation of the crater, which means that the nucleate boiling became more intense. This can be explained by the increase in heat flux due to the greater difference in the temperature. Also, there was a large amount of ethanol vapor above the liquid surface, and the splashed droplets were all small at higher liquid temperature. 


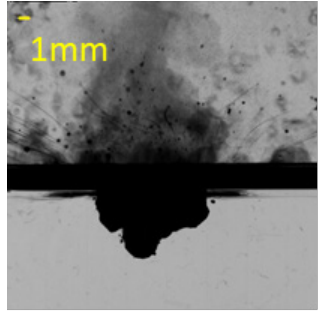

$W E=303$

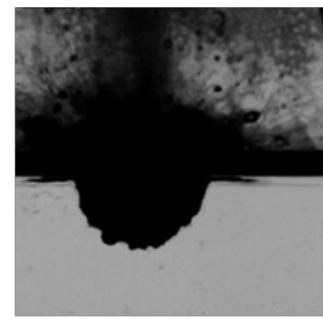

$W E=991$

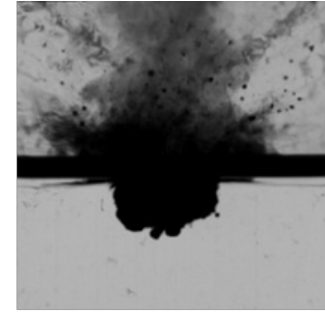

$W E=466$

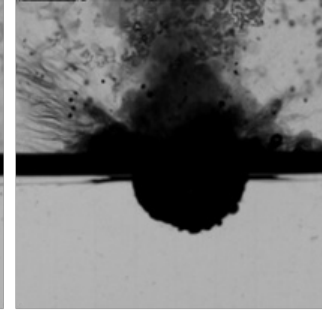

$W E=628$

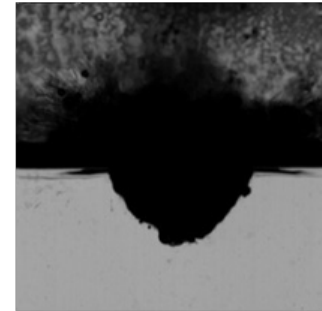

$W E=1191$

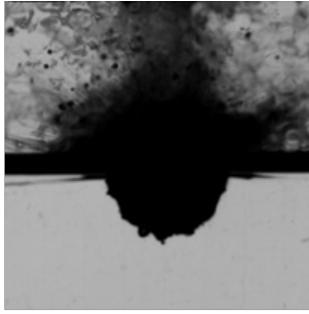

$W E=849$

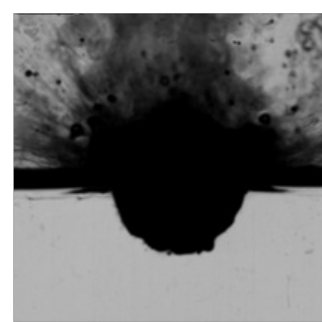

$W E=1343$

Fig. 9. Effects of $W E$ on the intensity of nucleate boiling $\left(230^{\circ} \mathrm{C}, \mathrm{t}=17 \mathrm{~ms}\right)$.

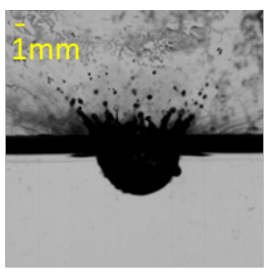

$200{ }^{\circ} \mathrm{C}$

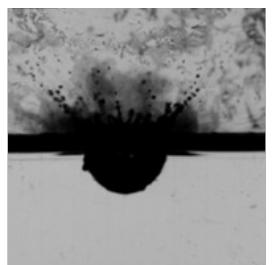

$210^{\circ} \mathrm{C}$

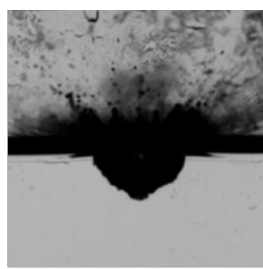

$220{ }^{\circ} \mathrm{C}$

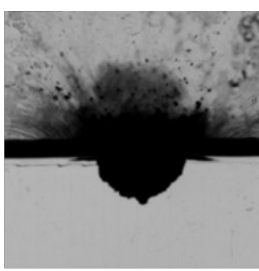

$230^{\circ} \mathrm{C}$

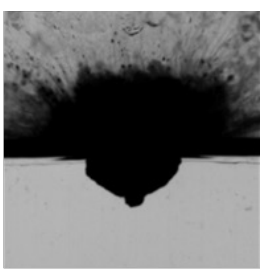

$245^{\circ} \mathrm{C}$

Fig. 10. Effects of temperature on the intensity of nucleate boiling ( $W E=1343, t=7 \mathrm{~ms})$.

\section{CONCLUSIONS}

The collision dynamics of a single ethanol droplet impacting a hot liquid surface were experimentally studied by varying the Weber number and liquid pool temperature. This study focuses on the phenomena around the liquid surface. Several interesting phenomena were observed and different from the previous studies, since the ethanol droplet density was lower than that of the glycerol pool while they were miscible to each other. Four phenomena were found in sequence: surface dissolving, penetrating dissolution, vapor explosion, and nucleate boiling occurred in sequence with the increasing pool temperature. The lower temperatures limits of liquid pool for both penetrating dissolution and the vapor explosion decreased with the increasing in the Weber number. The higher of Weber number and temperature increased the maximum crater volume and surface area but the growth rate. Additionally, the vapor explosion time sensitively increased with the increasing Weber number, while higher temperatures led to an earlier vapor explosion. The nucleate boiling intensity was enhanced by a lower Weber number and a higher liquid pool temperature.

The presence of the wall-attached oil film reduces the wall temperature, resulting in a decrease in oil film evaporation, which affects the formation of mixed gas in the subsequent working cycle of the engine, and increases the emissions of hydrocarbons and carbon monoxide (Drake et al., 2003). In this paper, by controlling the impact parameters and wall temperature, we found that at high temperature and high $W E$, vapor explosion and nucleate boiling of droplet would occur, which destroyed the wall-attached oil film and reduced the emission of aerosol particles. Additionally, most of the wall-attached fuel is on the piston crown and the cylinder wall, but the lubrication of the oil is in the contact part between the piston and the cylinder wall, so the wallattached fuel has almost no effect on the lubricating oil. 
Consequently, the Weber number, affected by fuel density, velocity characteristic length, and surface tension, was the important parameter to control the wall-attached fuel layer issue and might promote the lower carbon deposits and soot emissions. The low-density fuel content was also supported to have positive atomization phenomenon in the spray combustion. By increasing the cylinder temperature and increasing the WE, that is, increasing the injection speed, the vapor explosion and nucleate boiling can be realized, so the wall oil film can be reduced, and the fuel can be fully burned. However, since this experiment is a fundamental study, more specific experimental research should be carried out in practical applications.

\title{
NOMENCLATURE
}

\author{
WE Weber number \\ $\mathrm{T}$ pool temperature \\ $\checkmark \quad$ volume \\ $\mathrm{S}$ area \\ $\mathrm{t}$ time \\ I actual length of each pixel \\ $m \quad$ number of pixels \\ $n \quad$ number of rows

\section{Subscripts} \\ $i \quad$ row of the crater
}

\section{ACKNOWLEDGMENTS}

This work was supported by the National Natural Science Foundation of China under Grant No. 51806014. Any opinions, findings, and conclusions, or recommendations expressed in this publication are those of the authors and do not necessarily reflect the views of the National Science Foundation.

\section{REFERENCES}

Cen, C., Wu, H., Lee, C., Fan, L., Liu, F. (2019). Experimental investigation on the sputtering and micro-explosion of emulsion fuel droplets during impact on a heated surface. Int. J. Heat Mass Transfer 132, 130-137. https://doi.org/10.1016/j.ijheatmasstransfer.2018.12.007

Chen, J.H., Shen, Y.H., Yang, H.H., Lu, J.H., Wang, L.C., Hsieh, Y.K., Lee, C.F., Lin, S.L. (2020). Newer generation of scooters: Polychlorinated dibenzo- $p$-dioxin and dibenzofuran and polychlorinated biphenyl reductions. Aerosol Air Qual. Res. 20, 1495-1509. https://doi.org/10.4209/aaqr.2020. 04.0138

Chin, S.T., Lee, C.F.F. (2002). Numerical investigation of the effect of wall wetting on hydrocarbon emissions in engines. Proc. Combust. Inst. 29, 767-773. https://doi.org/10.1016/S15407489(02)80098-0

Drake, M.C., Fansler, T.D., Solomon, A.S., Szekely, G.A. (2003). Piston Fuel Films as a Source of Smoke and Hydrocarbon Emissions from a Wall-Controlled Spark-Ignited Direct-Injection Engine, Presented at the SAE 2003 World Congress \& Exhibition, pp. 2003-01-0547. https://doi.org/10.4271/2003-01-0547

Fan, X., Wang, C., Li, M., Chen, B., Wang, X., Zhang, A. (2018). Dynamic behavior of single droplet impacting on heptane pool with different depths. Eur. J. Mech. B. Fluids 72, 144-151. https://doi.org/10.1016/j.euromechflu.2018.05.009

Fan, X., Wang, C., Wang, X., Li, M., Shen, Z. (2019). Comparison of single droplet impact behaviors on the burning shallow/deep pool. Eur. J. Mech. B. Fluids 74, 191-199. https://doi.org/10.101 6/j.euromechflu.2018.11.016

Fan, X., Wang, C., Guo, F., Chen, B., Li, M. (2021). Water droplet impact on high-temperature peanut oil surface: The effects of droplet diameter and oil temperature. Int. J. Therm. Sci. 159, 
106601. https://doi.org/10.1016/j.ijthermalsci.2020.106601

Fang, L., Chen, G.D. (2019). Temperature charateristics of droplet impacting on static hot pool. Acta Phys. Sin. 68, 234702. https://doi.org/10.7498/aps.68.20190809

Hasegawa, K., Nara, T. (2019). Energy conservation during single droplet impact on deep liquid pool and jet formation. AIP Adv. 9, 085218. https://doi.org/10.1063/1.5113587

He, B.Q., Shuai, S.J., Wang, J.X., He, H. (2003). The effect of ethanol blended diesel fuels on emissions from a diesel engine. Atmos. Environ. 37, 4965-4971. https://doi.org/10.1016/j.atm osenv.2003.08.029

Kuo, Y.M., Wang, Y.K., Lin, S.L., Yin, L.T., Hsieh, Y.K. (2019). Air pollution characteristics of reclamation of refuse derived fuel (RDF) recovered from cutting oil waste. Aerosol Air Qual. Res. 19, 2576-2584. https://doi.org/10.4209/aaqr.2019.09.0481

Lan, M., Wang, X. (2014). A case study on the dynamic process of water drop impacting on heated wood surface. Case Stud. Therm. Eng. 2, 23-28. https://doi.org/10.1016/j.csite.2013.11.004

Lee, J.S., Weon, B.M., Park, S.J., Kim, J.T., Pyo, J., Fezzaa, K., Je, J.H. (2020). Air evolution during drop impact on liquid pool. Sci. Rep. 10, 5790. https://doi.org/10.1038/s41598-020-62705-5

Leng, L.J. (2001). Splash formation by spherical drops. J. Fluid Mech. 427, 73-105. https://doi.org/10.1017/S0022112000002500

Manzello, S.L., Yang, J.C. (2002). An experimental study of a water droplet impinging on a liquid surface. Exp. Fluids 32, 580-589. https://doi.org/10.1007/s00348-001-0401-8

Manzello, S.L., Yang, J.C., Cleary, T.G. (2003). On the interaction of a liquid droplet with a pool of hot cooking oil. Fire Saf. J. 38, 651-659. https://doi.org/10.1016/S0379-7112(03)00048-1

Mao, G., Zhang, C., Shi, K., Wang, P. (2019). Prediction of the performance and exhaust emissions of ethanol-diesel engine using different neural network. Energy Sources Part A https://doi.org/ 10.1080/15567036.2019.1656307

Martin, G.C., Mueller, C.J., Milam, D.M., Radovanovic, M.S., Gehrke, C.R. (2008). Early directinjection, low-temperature combustion of diesel fuel in an optical engine utilizing a 15-hole, dual-row, narrow-included-angle nozzle. SAE Int. J. Engines 1, 1057-1082. https://doi.org/10.4 271/2008-01-2400

Masum, B.M., Masjuki, H.H., Kalam, M.A., Rizwanul Fattah, I.M., Palash, S.M., Abedin, M.J. (2013). Effect of ethanol-gasoline blend on $\mathrm{NO}_{x}$ emission in SI engine. Renew. Sustain. Energy Rev. 24 209-222. https://doi.org/10.1016/j.rser.2013.03.046

Panão, M.R.O., Moreira, A.L.N. (2005). Flow characteristics of spray impingement in PFI injection systems. Exp. Fluids 39, 364-374. https://doi.org/10.1007/s00348-005-0996-2

Rein, M. (1993). Phenomena of liquid drop impact on solid and liquid surfaces. Fluid Dyn. Res. 12, 61-93. https://doi.org/10.1016/0169-5983(93)90106-K

Shinjo, J., Xia, J. (2017). Combustion characteristics of a single decane/ethanol emulsion droplet and a droplet group under puffing conditions. Proc. Combust. Inst. 36, 2513-2521. https://doi.org/ 10.1016/j.proci.2016.06.191

Stevens, E., Steeper, R. (2001). Piston Wetting in an Optical DISI Engine: Fuel Films, Pool Fires, and Soot Generation, Presented at the SAE 2001 World Congress, pp. 2001-01-1203. https://doi.org/10.4271/2001-01-1203

Tsai, J.H., Lin, S.L., Mwangi, J.K., Chen, C.Y., Wu, T.S. (2015). Energy saving and pollution reduction by adding water containing iso-butanol and iso-propyl alcohol in a diesel engine. Aerosol Air Qual. Res. 15, 2115-2128. https://doi.org/10.4209/aaqr.2015.06.0409

Tsai, J.H., Chen, Y.R., Chen, S.J., Lin, S.L., Huang, K.L., Lin, C.C., Chiu, J.Y. (2020). Characteristics of emissions from a portable two-stroke gasoline engine. Aerosol Air Qual. Res. 20, 630-642. https://doi.org/10.4209/aaqr.2019.12.0650

Wang, B., Mosbach, S., Schmutzhard, S., Shuai, S., Huang, Y., Kraft, M. (2016). Modelling soot formation from wall films in a gasoline direct injection engine using a detailed population balance model. Appl. Energy 163, 154-166. https://doi.org/10.1016/j.apenergy.2015.11.011

Wang, Z., Liu, H., Reitz, R.D. (2017a). Knocking combustion in spark-ignition engines. Prog. Energy Combust. Sci. 61, 78-112. https://doi.org/10.1016/j.pecs.2017.03.004

Wang, Z., Wang, X., Zhu, P., Chen, P., Zhao, X., Zhang, H. (2017b). Experimental study on the vapor explosion process of a water drop impact upon hot molten-ghee surface. J. Loss Prev. Process Ind. 49, 839-844. https://doi.org/10.1016/j.jlp.2017.03.013

Xu, M., Wang, C., Lu, S. (2016). Experimental study of a droplet impacting on a burning fuel liquid 
surface. Exp. Therm. Fluid Sci. 74, 347-353. https://doi.org/10.1016/j.expthermflusci.2016.01. 002

Xu, M., Wang, C., Lu, S. (2017). Water droplet impacting on burning or unburned liquid pool. Exp. Therm. Fluid Sci. 85, 313-321. https://doi.org/10.1016/j.expthermflusci.2017.02.021

Xu, M., Li, C., Wu, C., Chen, X., Lu, S. (2018a). Regimes during single water droplet impacting on hot ethanol surface. Int. J. Heat Mass Transfer 116, 817-824. https://doi.org/10.1016/j.ijheatm asstransfer.2017.09.030

Xu, M., Zhang, J., Wu, C., Li, C., Chen, X., Lu, S. (2018b). Collision dynamics of a single water droplet impinging on a high-temperature pool of oil. Acta Mech. 229, 1567-1577. https://doi.org/10.1 007/s00707-017-2071-5

Xu, M., Zhang, J., Chen, R., Lu, S. (2019). Single droplet with or without additives impacting on high-temperature burning liquid pool. Int. J. Heat Mass Transfer 139, 77-86. https://doi.org/10. 1016/j.ijheatmasstransfer.2019.04.145

Yao, M., Zheng, Z., Liu, H. (2009). Progress and recent trends in homogeneous charge compression ignition (HCCl) engines. Prog. Energy Combust. Sci. 35, 398-437. https://doi.org/10.1016/j.pec s.2009.05.001 